\title{
Analysis of Smoke Distribution in the Subway Station with Various Main Tunnel Ventilations
}

\author{
Yong-Jun Jang, Ji-Min Ryu, Sung-Huk Park and Dong-Hoe Koo \\ Korea Railroad Research Institute, Railroad Safety Center, Gyeonggi-do 437-757, South Korea
}

Received: December 12, 2014 / Accepted: February 02, 2015 / Published: April 30, 2015.

\begin{abstract}
Fire-driven flow analysis in the underground subway station has been performed with various main tunnel ventilations. Shin-gum-ho station (depth: $46 \mathrm{~m}$ ) in Seoul is selected as a simulation model. The ventilation mode is assumed to be emergency state. Various main tunnel ventilations are applied to operate in a proper way for helping of smoke exhaustion in platform. The entire station is covered for simulation. Ventilation diffusers are modeled as 95 square shapes of $0.6 \mathrm{~m} \times 0.6 \mathrm{~m}$ in the lobby and as 222 square shapes of $0.6 \mathrm{~m} \times 0.6 \mathrm{~m}$ and four rectangular shapes of $1.2 \mathrm{~m} \times 0.8 \mathrm{~m}$ in the platform. The total of 7.5 million grids is generated and whole domain is divided to 22 blocks for MPI (massage passing interface) efficiency of calculation. LES (large eddy simulation) is applied to solve the momentum equation. Smagorinsky model $\left(C_{s}=0.2\right)$ is used as SGS (subgrid scale) model. The distribution of CO (carbon monoxide) is calculated for various capacity of main tunnel ventilation and compared with each other.
\end{abstract}

Key words: Subway station, main tunnel ventilation, fire-driven flow, LES.

\section{Introduction}

Fire disaster in Daegu subway station, occurred in 2003, has enforced to establish the several laws for fire safety standard in railway system in Korea. However, the fire-safety measures for subway station and subway tunnel have not been much arranged yet in Korea.

Many researchers have challenged the fire-driven flow analysis in tunnel. Hwang and Edwards [1] studied the hot stratified flow and ventilated flow in tunnel. They simulated the back-layer flow phenomena in tunnel. Hwang and Wargo [2] showed the thermally generated reverse stratified layers in fire tunnel using experimental method. Woodburn and Britter $[3,4]$ calculated the fire-driven flow in tunnel. Jang et al. [5] studied the back-layer flow phenomena in the straight tunnel using LES (large eddy simulation) and RANS (Reynolds Averaged Navier-Stokes Equations). They compared the

Corresponding author: Yong-Jun Jang, principal researcher, research field: thermo-fluid dynamics in railway. E-mail: jangyj@krri.re.kr. simulated results with experimental data and showed that LES produced better results than RANS. Fletcher et al. [6] experimentally investigated the tunnel fire using a pool fire. They also simulated the same fire-driven flow as their experiments using $k-\varepsilon$ model and compared the results. Gao et al. [7] theoretically studied the tunnel fire flow which was experimentally done by Fletcher et al. [6]. They employed LES method and compared the results with experimental data. Jang et al. [8] studied the ventilated and fire-driven flow in the deeply underground subway station using LES and parallel computing. Jang et al. [9] experimentally investigated the ordinary and emergency ventilation system in deeply underground subway station to study the exact ventilation capacity of subway station.

In this research, Shin-gum-ho subway station, its depth is $46 \mathrm{~m}$, is been selected as a simulation study for investigation of ventilated and fire-driven flow because the passenger evacuation would be concerned when a fire break out in this station. Currently, ventilation operation mode in Shin-gum-ho station is set up as a 
full exhaustion mode in the platform in case of platform-fire emergency. Furthermore, various main tunnel ventilations are applied to be operated as prescribed in Table 1 for helping of smoke exhaustion in platform. Fire is assumed to break out inside train which is parked in platform. Fire strength is $10 \mathrm{MW}$. The LES method in FDS (fire dynamics simulator) code is used to simulate the fire-driven flow in this station. Parallel computation is employed to reduce the calculation time.

\section{Modeling of Station}

The total number of floors in Shin-gum-ho station is 8. The first and second floor undergrounds are lobby and the eighth floor underground is platform. Fig. 1 shows the overall view and ventilation condition for emergency in Shin-gum-ho station. The pressurized air is supplied in the first and second floor lobby. The contaminated air by smoke in the platform is exhausted through the ventilation. Fig. 2 shows the conditions for various main tunnel ventilation and capacity which is well described in Table 1. Fig. 3 shows the ventilation distribution in the first and second floor undergrounds. In ordinary case, blue ventilation is used as air supply and red ventilation is used as air exhaustion. In emergency case, however, all ventilations are used as air supply. Ventilation diffusers are modeled as 95 square shapes of $0.6 \mathrm{~m}(x)$ $\times 0.6 \mathrm{~m}(y)$ in the lobby (Fig. 3) and as 222 square shapes of $0.6 \mathrm{~m}(x) \times 0.6 \mathrm{~m}(y)$ and four large rectangular shapes of $1.2 \mathrm{~m}(x) \times 0.8 \mathrm{~m}(y)$ in the platform (Fig. 4).

Table 1 Cases for main tunnel ventilation.

\begin{tabular}{llll}
\hline Cases & Descriptions & $\begin{array}{l}\text { Tunnel ventilation } \\
\text { Capacity }\end{array}$ & Figure \\
\hline 1 & $\begin{array}{l}\text { No main tunnel } \\
\text { ventilation }\end{array}$ & 0 & Fig. 2a \\
2 & One side exhaustion & $-7,000 \mathrm{~m}^{3} / \mathrm{min}$ & Fig. 2b \\
& $\begin{array}{l}-7,000 \mathrm{~m}^{3} / \mathrm{min} \\
\text { and }\end{array}$ & Fig. 2c \\
3 & Two sides & $\begin{array}{l}-10,500 \mathrm{~m}^{3} / \mathrm{min} \\
\text { exhaustion }\end{array}$ & \\
& $\begin{array}{l}\text { One side exhaustion } \\
\text { and one side air }\end{array}$ & $\begin{array}{l}-7,000 \mathrm{~m}^{3} / \mathrm{min} \\
\text { and } \\
+2,400 \mathrm{~m}^{3} / \mathrm{min}\end{array}$ & Fig. 2d \\
& supply & & \\
\hline
\end{tabular}

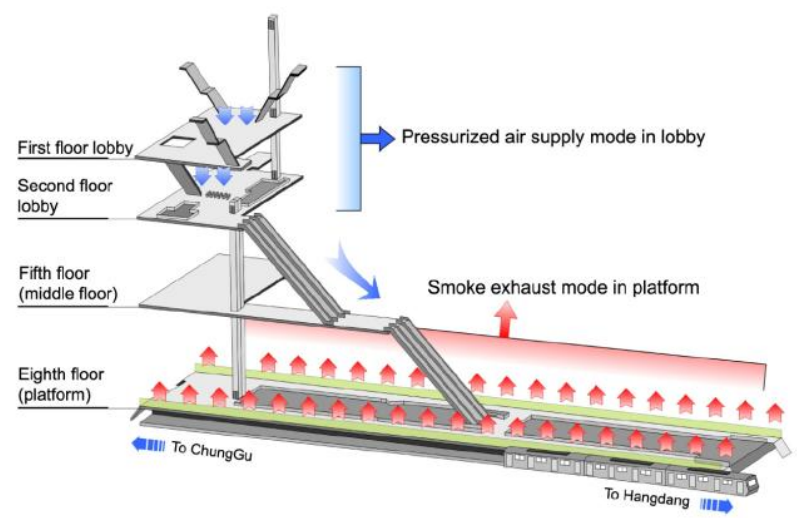

Fig. 1 Ventilation fan modes in Shin-gum-ho station for emergency state.

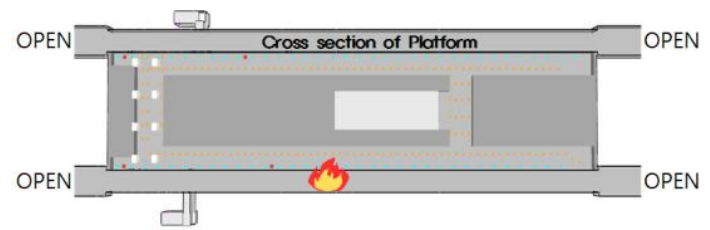

(a) Case 1

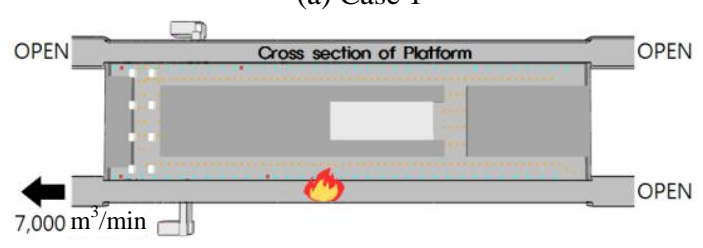

(b) Case 2

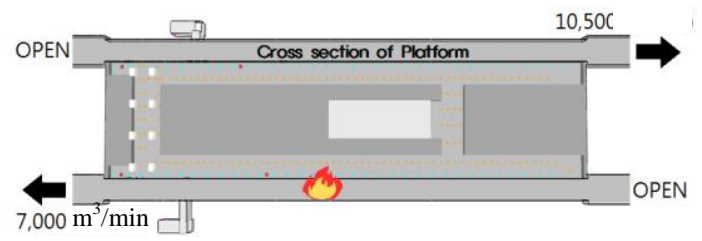

(c) Case 3

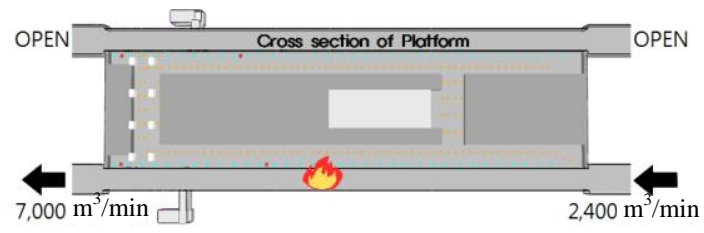

(d) Case 4

Fig. 2 Case study of various main tunnel ventilations.

\section{Governing Equation and Numerical Methods}

The FDS code solves numerically a form of Navier-Stokes equations and the core algorithm for momentum equations is an explicit predictor-corrector scheme that uses second order accurate finite-difference approximation. The flow variables are updated in time using an explicit second-order Runge-Kutta scheme. 


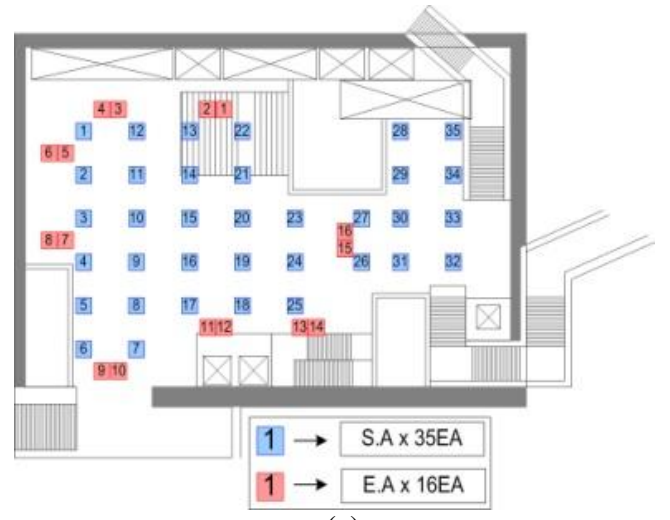

(a)

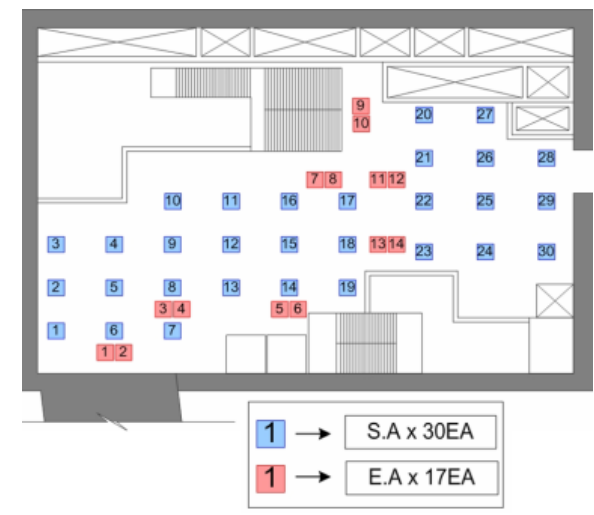

(b)

Fig. 3 Diffuser arrangement of (a) the first floor underground and (b) of the second floor underground.

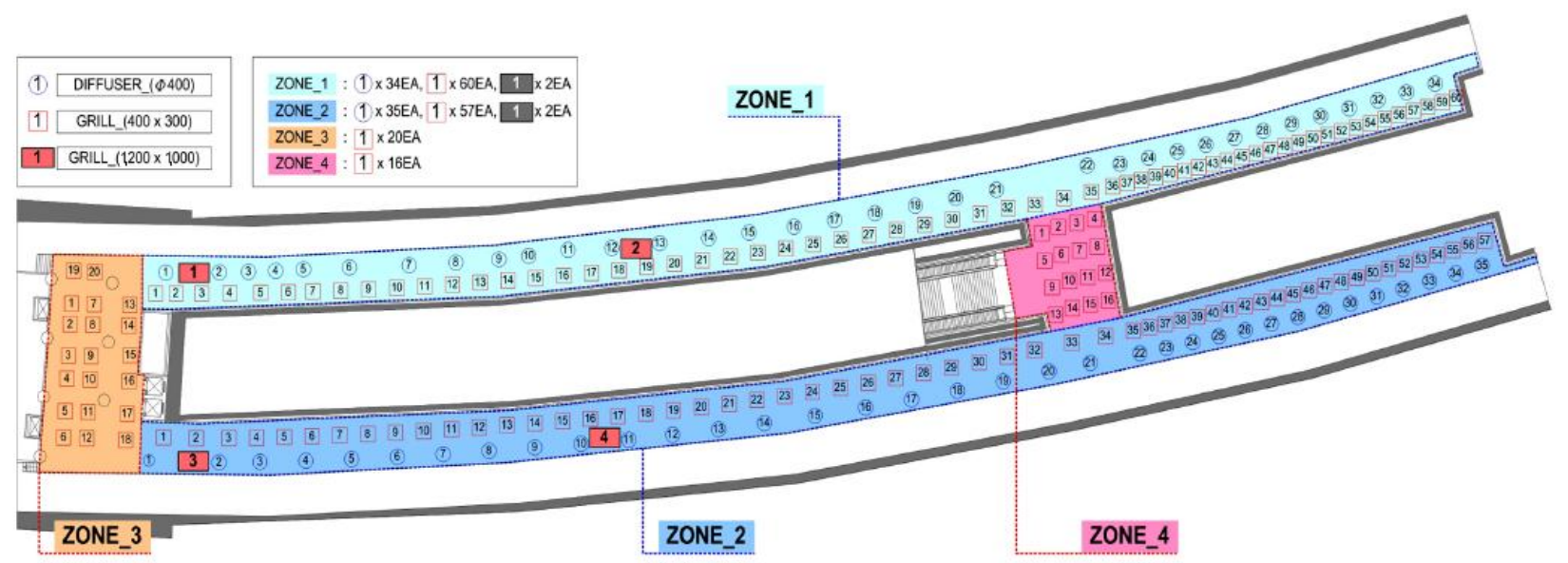

Fig. 4 Diffuser arrangement in the platform of Shin-gum-ho station.

Turbulence is treated by means of the Smagorinsky form of LES.

The governing equations [10] for LES in FDS are as follows:

$$
\begin{gathered}
\frac{\mathrm{D} \overline{U_{i}}}{\mathrm{D} t}=-\frac{1}{\rho} \frac{\partial \bar{P}}{\partial x_{i}}+\frac{\partial}{\partial x_{j}}\left\{v\left(\frac{\partial \overline{U_{i}}}{\partial x_{j}}+\frac{\partial \overline{U_{j}}}{\partial x_{i}}\right)-\tau_{i j}\right\} \\
\tau_{i j}=\overline{U_{i} U_{j}}-\overline{U_{i}} \overline{U_{j}} \\
\tau_{i j}-\frac{1}{3} \delta_{i j} \tau_{k k}=-2 v_{t} \overline{S_{i j}} \\
\overline{S_{i j}}=\frac{1}{2}\left(\frac{\partial \overline{U_{i}}}{\partial x_{j}}+\frac{\partial \overline{U_{j}}}{\partial x_{i}}\right)
\end{gathered}
$$

In Eqs. (1)-(4), $\rho, \bar{P}, \overline{U_{i}}, \tau_{i j}, \overline{S_{i j}}$ and $v_{t}$ denote density, mean static pressure, mean velocity, turbulent fluctuation tensor, strain rate tensor and turbulent viscosity, respectively.

Where, $v_{t}$ should be modeled, Smagorinsky model [11] is employed in FDS code:

$$
\begin{gathered}
v_{t}=\left(C_{s} \bar{\Delta}\right)^{2}|\bar{S}| \\
|\bar{S}|=\left(2 S_{i j} S_{i j}\right)^{1 / 2} \\
\bar{\Delta}=(\Delta x \Delta y \Delta z)^{1 / 3}
\end{gathered}
$$

where, $C_{s}$ is an empirical constant and is 0.2. In Eq. (7), $\Delta x, \Delta y, \Delta z$ denote grid distances in $\mathrm{x}, \mathrm{y}, \mathrm{z}$ coordinates, respectively.

The grid size is then selected to be $0.2 \mathrm{~m}$ and the total grid numbers are 750 millions (Fig. 5). The whole domain is divided to 22 blocks and computed on 10 CPUs in parallel using MPI (massage passing interface). 


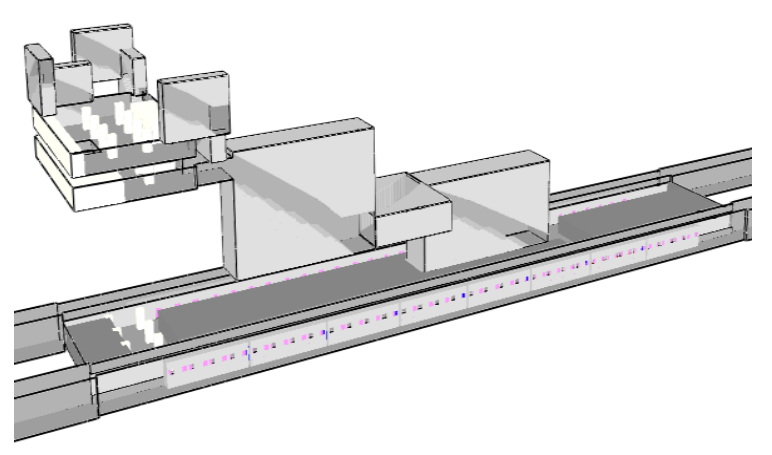

Fig. 5 Grid modeling for Shin-gum-ho subway station.

\section{Results and Discussion}

Fig. 6 shows velocity contour and vectors in the lobby with no main tunnel ventilation. The total air supply and exhausted ventilation rate is $42,126 \mathrm{~m}^{3} / \mathrm{h}$ and $22,561 \mathrm{~m}^{3} / \mathrm{h}$ in the lobby, respectively. The ventilated and outside flow are strongly mixed in the first lobby and then sucked into the second floor through the passage. The cooled and outside air flows go down to the platform along the stair way. Fig. 7 shows the fire-driven flow in platform with no main tunnel ventilation. Fire is assumed to break out in the middle of train which is parked in platform. The fire strength is $10 \mathrm{MW}$. All PSDs (platform screen doors) are open. The purple color means the iso-surface of temperature $\left(100{ }^{\circ} \mathrm{C}\right)$ and the black particles present the distribution of soot due to the platform fire. The hot smoke goes up to the ceiling because of strong buoyancy effect and then spread out along the tunnel. The soot from smoke overflows out to the platform and then tries to go up to the stair way. The purpose of main tunnel ventilation is to prevent the spread of smoke in the platform. Fig. 8 shows the soot distribution in the platform. The smoke well propagates into the platform with no main tunnel ventilation (Fig. 8a). In case of operation of main tunnel ventilation, however, the smoke is limited in the fire region and sucked into the tunnel due to the tunnel ventilation and not well propagates into the platform (Figs. 8b-8d). It is interesting to see that the smoke is slightly propagated to the opposite side of platform in case of three in

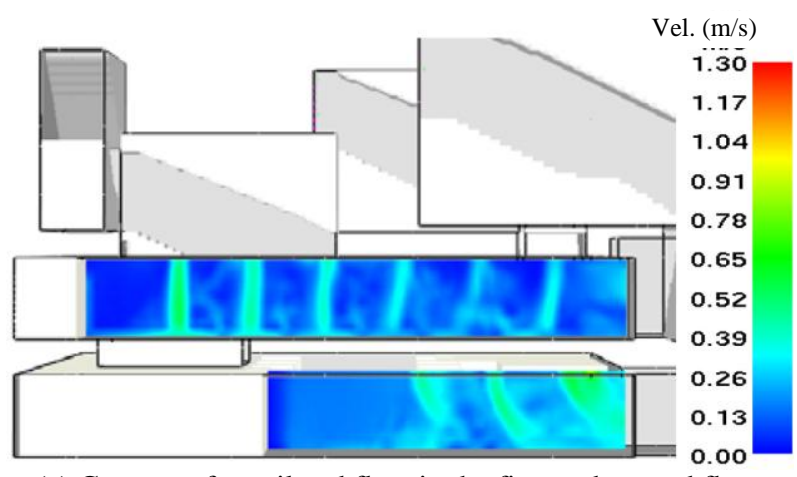

(a) Contour of ventilated flow in the first and second floor lobby $(50 \mathrm{~s})$
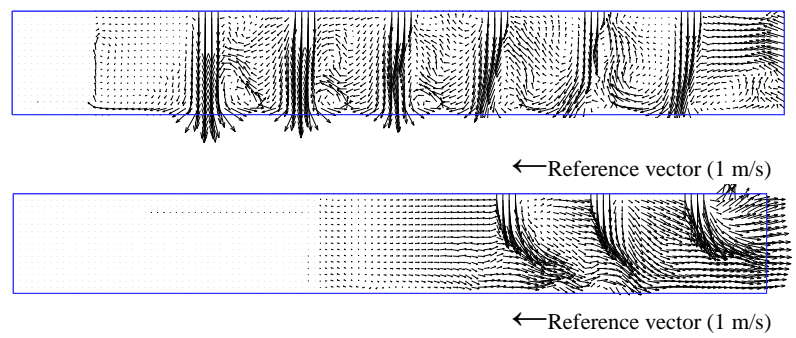

(b) Velocity vectors of ventilated flow in the first (up) and second (down) floor lobby (50 s)

Fig. 6 Contour and velocity vectors of ventilated flow in the first and second floor lobby (50 s) with no main tunnel ventilation.

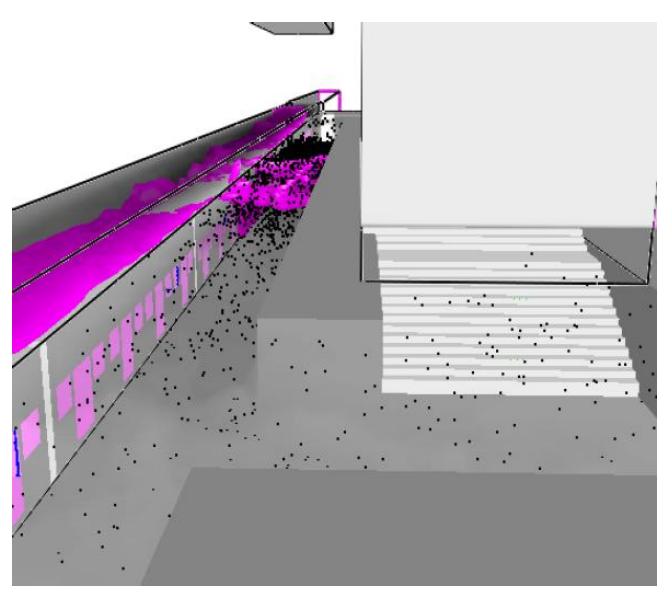

Fig. 7 Temperature iso-surface $\left(100{ }^{\circ} \mathrm{C}\right)$ of smoke and soot particles in the platform due to the fire in the train with no main tunnel ventilation.

which two-way tunnel exhaustion is operated. It is clearly seen that the main tunnel ventilation plays an important role to eliminate the smoke in the platform and help the passenger escape to safety zone. Fig. 9 shows CO (carbon monoxide) distribution in the platform. The $\mathrm{CO}$ densities are calculated at seven points in the platform. The soot goes out through the PSD door from the train and get into the platform. 


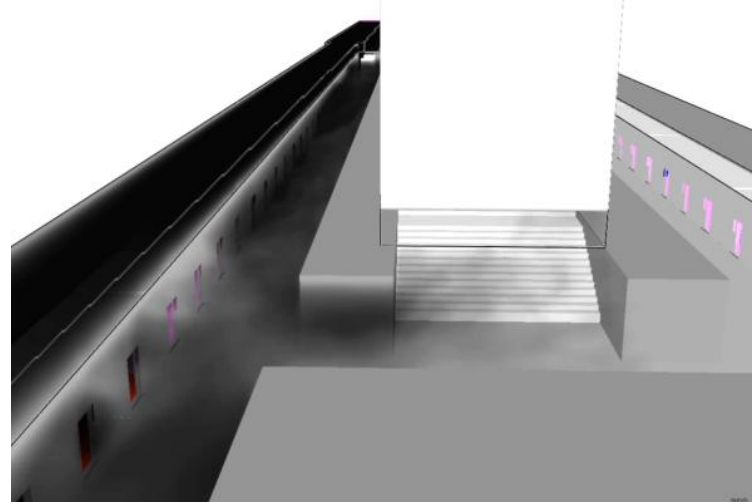

(a) Case 1

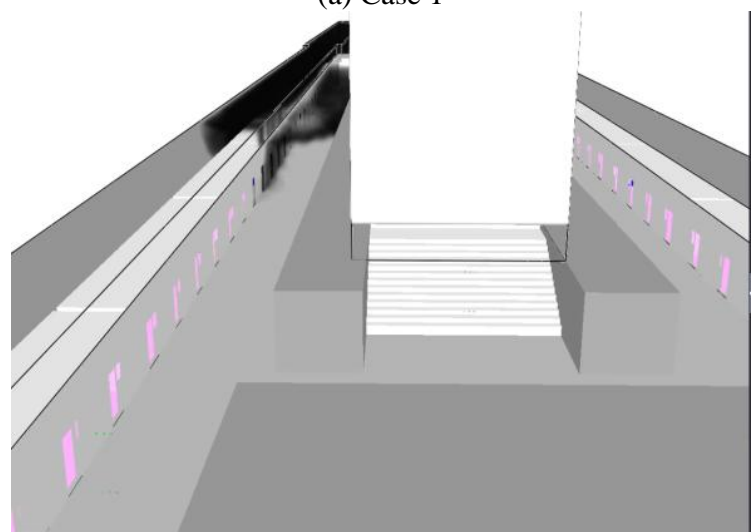

(b) Case 2

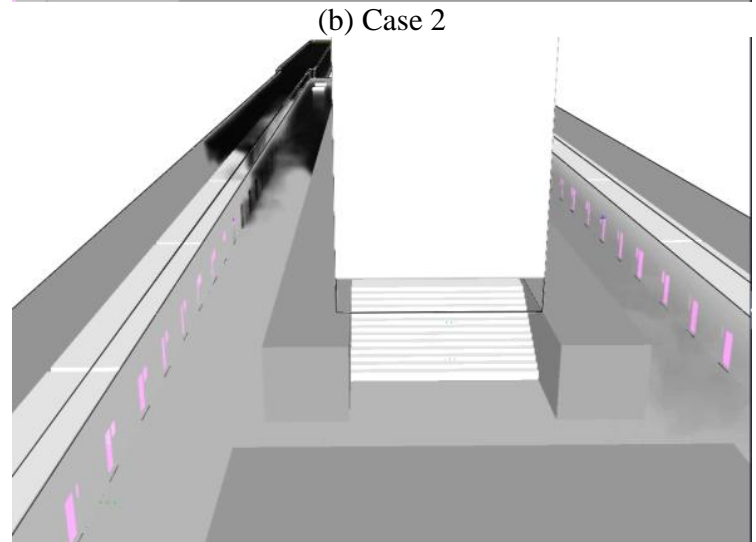

(c) Case 3

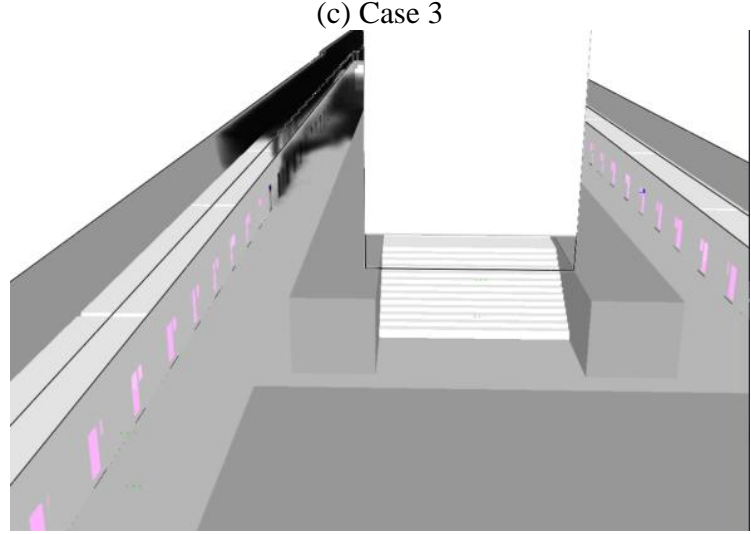

(d) Case 4

Fig. 8 Soot distribution in the platform with various main tunnel ventilations.

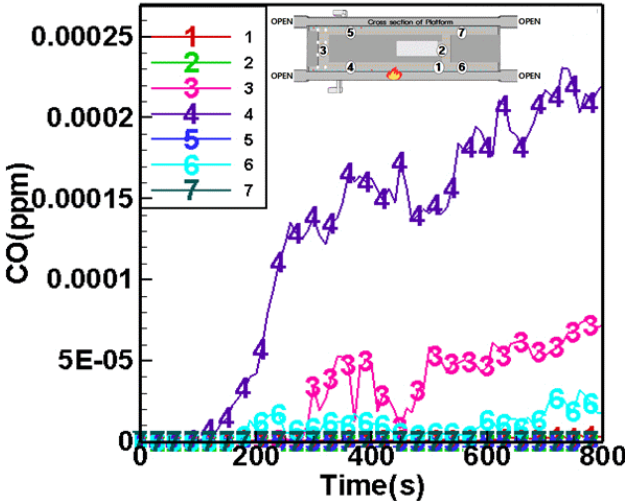

(a) Case 1

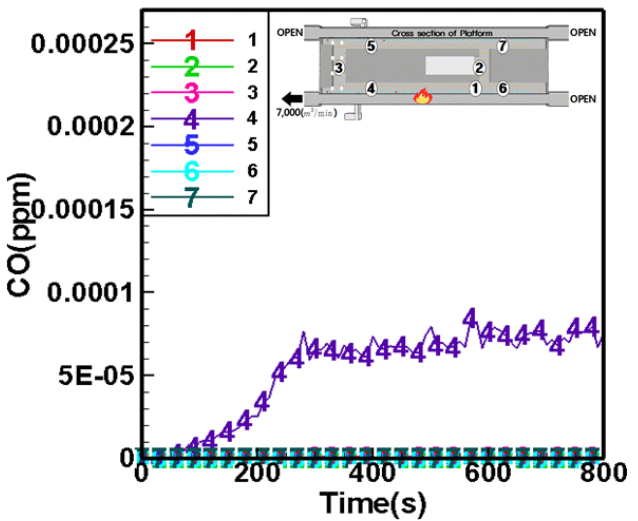

(b) Case 2

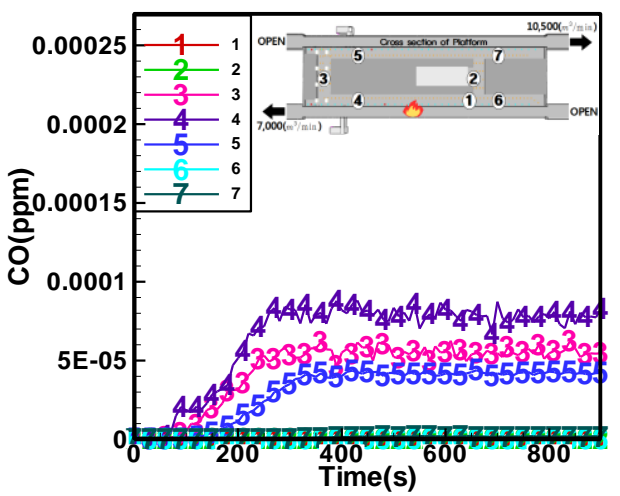

(c) Case 3

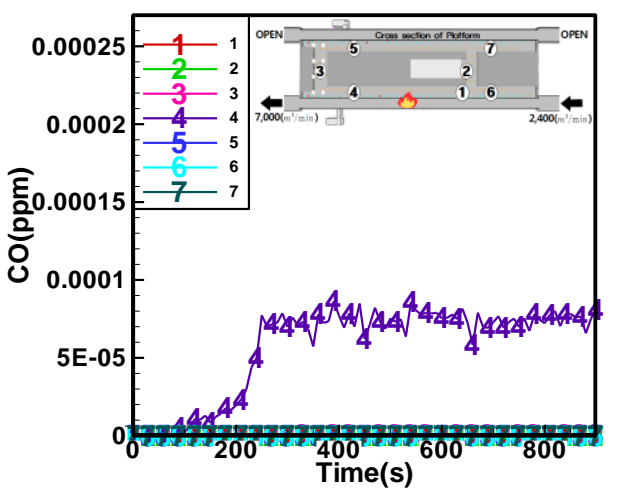

(d) Case 4

Fig. 9 Calculated $\mathrm{CO}$ in the platform with various main tunnel ventilations. 
Without the main tunnel ventilation, $\mathrm{CO}$ distribution is three times higher than the cases of tunnel ventilation in the platform (Fig. 9a). With the main tunnel ventilation, the $\mathrm{CO}$ is sucked into the tunnel and the $\mathrm{CO}$ density become lower in the platform (Figs. 9b-9d).

\section{Conclusions and Summary}

Fire-driven flows with various main tunnel ventilations in the subway station are simulated. The deeply underground subway station (Shin-gum-ho station) is selected and modeled. The thermal-fluid behavior due to the fire is analyzed and then the distribution of $\mathrm{CO}$ is calculated. LES method is employed to simulate the fire-driven flow.

The flow in the lobby is strongly mixed with ventilated fresh air flow and then sucked down to the stairway which provides fresh air to passenger evacuating from platform. In the platform, the smoke is well propagated to the platform with no main tunnel ventilation. The operation of main tunnel ventilation prevents the smoke from propagating in the platform and sucks the smoke into the tunnel. Without the main tunnel ventilation, $\mathrm{CO}$ distribution is three times higher than the cases of tunnel ventilation in the platform. The optimized cases for main tunnel ventilation should be further studied to reduce the $\mathrm{CO}$ densities in the platform in case of station fire.

The LES methods properly calculate the fire-driven flow in the station. The results could be helpful to understand the fire-driven flow in the station with various main tunnel ventilations.

\section{Acknowledgments}

This research is supported by a grant (PK1506C9) from Korea Railroad Research Institute.

\section{References}

[1] Hwang, C. C., and Edwards, J. C. 2005. "The Critical Ventilation Velocity in Tunnel Fires-A Computer Simulation." Fire Safety Journal 40 (3): 213-44.

[2] Hwang, C. C., and Wargo, J. D. 1986. "Experimental Study of Thermally Generated Reverse Stratified Layers in a Fire Tunnel." Combustion and Flame 66 (2): 171-80.

[3] Woodburn, P. J., and Britter, R. E. 1996. "CFD Simulations of a Tunnel Fire-Part I." Fire Safety Journal 26 (1): 35-62.

[4] Woodburn, P. J., and Britter, R. E. 1996. "CFD Simulations of a Tunnel Fire-Part II." Fire Safety Journal 26 (1): 63-90.

[5] Jang, Y. J., Kim, H. B., Kim J. H., and Han, H. Y. 2009. "Comparative Study on the Numerical Simulation for the Bake-Layer of the Tunnel Fire-Driven Flow with LES and RANS." Transactions of the KSME (B) 33 (3): 156-63.

[6] Fletcher, D. F., Kent, J. H., and Apte, V. B. 1994. "Numerical Simulations of Smoke Movement from a Pool Fire in a Ventilated Tunnel." Fire Safety Journal 23 (3): 305-25

[7] Gao, P. Z., Liu, S. L., Chow W. K., and Fong, N. K. 2004. "Large Eddy Simulation for Studying Tunnel Smoke Ventilation." Tunneling and Underground Space Technology 19 (6): 577-86.

[8] Jang, Y. J., Kim, H. B., and Lee, C. H. 2009. "The Numerical Simulation of Fire Driven Smoke and Heat Flow in the Deeply Underground Subway Station Using a Linux Clustering Computer." In Proceedings of the KSME (Korean Society of Mechanical Engineering) Spring Annual Meeting KSME 09TE063, 465-71.

[9] Jang, Y. J., Lee, H. S., and Park, D. S. 2012. "Experimental Study for the Capacity of Ordinary and Emergency Ventilation System in Deeply Underground Subway Station." Journal of the Korean Society for Railway 15 (6): 579-87.

[10] McGrattan, K., McDermontt, R., Hostikka, S., and Floyd, J. 2010. Fire Dynamics Simulator (Ver. 5) User's Guide. Gaithersburg: NIST (National Institute of Standards and Technology).

[11] Smagorinsky, J. 1963. "General Circulation Experiments with the Primitive Equation I, the Basic Experiment." Monthly Weather Review 91 (3): 99-164. 